\title{
VARIACIÓN EN LA COMPOSICIÓN ISOENZIMÁTICA EN LA POBLACIÓN DE PINUS HARTW EG IILINDL, DEL
PICO DE ORIZABA, VERACRUZ
}

\section{L aura Y. Solís R $\operatorname{amos}^{1}$ y L ourdes G . Iglesias Andreu ${ }^{2}$}

\author{
${ }^{1}$ Tesista Maestría Ecología Forestal, ${ }^{2}$ In stituto de Genética Forestal, Universidad \\ Veracruzana (MÉxico) \\ EMAIL:CATLEYASP@HOTMAIL.COM; LGEOR@HOTMAIL.COM
}

\section{INTRODUCCIÓN}

L a caracterización eidentificación depoblaciones forestales generalmente se basa en la descripción de características morfológicas de las plantas; pero su uso es limitado debido a que por lo regular estas características se ven afectadas por el ambiente en donde se desarrolla el organismo (Stegeman, 1984; I glesias y A paricio, 2001).

Como alternativa, en las últimas dos décadas sehan desarrollado y aplicado con éxito los marcadores isoenzimáticos para estudio de la variación en poblaciones forestales (Parker et al., 1997; Schmidtling et al., 1999).

U na gran ventaja de la caracterización isoenzimática comparada con los datos de características morfológicas, es que las isoenzimas por ser productos primarios de los genes, son menos afectadas por el ambiente; además, como la expresión de las enzimas es generalmente codominante, es posible identificar tanto genotipos homocigotos como heterocigotos. EI uso de las isoenzimas como marcadores se debe a que están libres de asociaciones deletéreas 0 efectos epistáticos/pleiotrópicos los cuales ca- racterizan a los marcadores morfológicos (A siedu, 1992; I glesias y R ojas, 1992).

Es por ello que se han desarrollado en coníferas y particularmente en el género Pinus numerosos estudios isoenzimáticos que han demostrado la existencia de una amplia variabilidad intrapoblacional (H amrick et al., 1981). Sin embargo pese a su importancia la mayoría de los estudios que se han realizado en la especie de P. hartw egii han sido efectuadas medianteel empleo de marcadores de tipo morfológicos (Pérez, 1984 y Bonilla, 1993, I glesias, Solís y H ernández, 2001, datos no publicados).

Estudios previos efectuados en las poblaciones de Pinus hartw egii ubicadas en el $C$ ofre de Perote y Pico de 0 rizaba, Ver., han mostrado que las mismas se encuentran seriamente afectadas, dado el bajo porcentaje de germinación (menor de un 10\% ) así como el elevado número de semillas vacías que sobrepasa la cifra del $50 \%$ en dichas poblaciones constituyen, al parecer, manifestaciones del fenómeno de depresión consanguínea bastante común en especies de coníferas (Williams y Savolaienen, 1996) que están ocasionando una sensible disminución en la producción y calidad de la semilla de estas 
poblaciones que están provocando una seria reducción de las tasas reproductivas en dichas poblaciones (I glesias et al., 1999; Solís e I glesias, datos no publicados). Esta problemática es preocupante dada la restringida distribución de la especie en el país, así como por su reducida población en el estado de Veracruz.

Teniendo en cuenta todo lo anterior se desarrolló el presente trabajo con el fin de conocer y describir la variación en la composición esterasas en megagametofitos de árboles provenientes de la población de Pinus hartwegii del Pico de 0 rizaba, Ver.

\section{MATERIALES Y MÉTODOS}

EI presente trabajo se efectuó en el L aboratorio de $\mathrm{M}$ arcadores $\mathrm{M}$ oleculares del Instituto de Genética Forestal de la U niversidad Veracruzana en X alapa, Ver. Se colectaron semillas de 20 árboles de Pinus hartwegii L indl. de la población del Pico de 0 rizaba, Veracruz, $M$ éxico, localizada entre los $19001^{\prime}$ de latitud $\mathrm{N}$ orte y $97^{\circ} 15^{\prime}$ de longitud $\mathrm{O}$ este. EI sitio presenta suelos profundos, arenosos y con buen drenaje, precipitación media anual de 2091.1 $\mathrm{mm}$, temperatura media anual de 18.8 C , y la población bajo estudio se encuentra entre los 3500 y 3800 msnm (SM N , 1984).

$\mathrm{L}$ as semillas debidamente tratadas e identificadas fueron almacenadas en refrigeración a $4^{\circ} \mathrm{C}$ hasta su uso. Posteriormente se colocaron en cajas Petri con agrolita para su germinación, hasta que la radícula al canzó una longitud de 3 a $5 \mathrm{~mm}$. Para extraer las proteínas de las semillas y hacer el corrimiento el ectroforético delas muestras, se removió la testa y el embrión se separó del tejido del megagametofito. Posteriormente se homogenizaron en frío, los extractos de megagametofito en tampón fosfato $0.2 \mathrm{M} \mathrm{pH}$ 7.5. L os extractos obtenidos se centrifugaron a 13,000 rpm durante 10 minutos y posteriormente se sometió el sobrenadante a electroforésis.

$L$ a electroforésis se realizó en un sistema discontinuo de geles de poliacrilamida en lámina vertical (PAGE) siguiendo el proce- dimiento descrito por I glesias et al. (1974).

$L$ a tinción de las isoenzimas esterasas (E st: EC 3.1.1.2) serealizó siguiendo el procedimiento de Iglesias (1986). El revelado se inició al agregar el sustrato de la enzima de interés a la lámina del gel colocado en una charola de plástico detinción de $17 \times 11 \mathrm{~cm}$. Se al macenó hasta que las bandas fueron evidentes y nítidas en el gel, se retiró de la solución y se lavó con agua corriente.

L os patrones de bandas se dibujaron sobre papel milimétrico, designando como cero el punto de unión del gel de compactación y separación y como 100 la posición de la banda 1, de más rápida migración anódica.

Para el establecimiento de los patrones de bandas de cada genotipo en estudio se registró el polimorfismo detectado sobre la base de número, posición relativa e intensidad de tinción de cada banda detectada. Para esta última se siguió la escala de tres grados: 1 = tenuemente teñida, 2 = medianamente teñida y $3=$ muy teñida. Se determinaron los genotipos individuales y sobre esta base se calcularon los parámetros poblacionales: porcentaje de polimorfismo (PP), de acuerdo con $\mathrm{H}$ endrick (1985), el índice de heterocigocidad esperada $\left(\mathrm{H}_{\mathrm{e}}\right)$ de acuerdo con la fórmula de $\mathrm{N}$ ei (1978) corregida para muestras pequeñas y el número promedio deal elos por locus (N PA L) deacuerdo con lo propuesto por Ayala y K iger (1984).

\section{RESULTADOS Y DISCUSIÓN}

L os resultados obtenidos revelaron la existencia de un total de ocho bandas con actividad esterasa bien definidas, las que se agruparon en cuatro zonas electroforéticas (Figura 1) según la movilidad electroforética en: Est1, E st2, E st3 y E st4. En la zona E st1 de más lenta movilidad aniónica se detectaron dos bandas (bandas 1 y 2 ) con valores de $R f$ de 0.38 y 0.43 $\mathrm{cm}$, la primera medianamente teñida (escala 2) y la segunda altamente teñida (escala 3); En las zonas Est2 y Est3 se detectaron cuatro bandas (bandas 3,4,5 y 6) con valores de movilidades electroforéticas de: $0.51,0.60$ y $0.65,0.70 \mathrm{~cm}$ 
respectivamente. $\mathrm{L}$ a banda 3 resultó tenuemente teñida (escala 1), mientras que el resto de las bandas mostraron una elevada intensidad de tinción (escala 3). D entro de estas últimas las bandas 4 y 5 mostraron una coloración roja que denota la presencia de actividad colinesterasa. Por último en la zona Est4 se detectaron dos bandas (bandas 7 y 8) la primera con mayor intensidad de tinción (escala 3) a diferencia de la banda 8 que resultó medianamente teñida (escala 2). E stas bandas mostraron movilidades electroforéticas de 0.77 a $0.81 \mathrm{~cm}$.

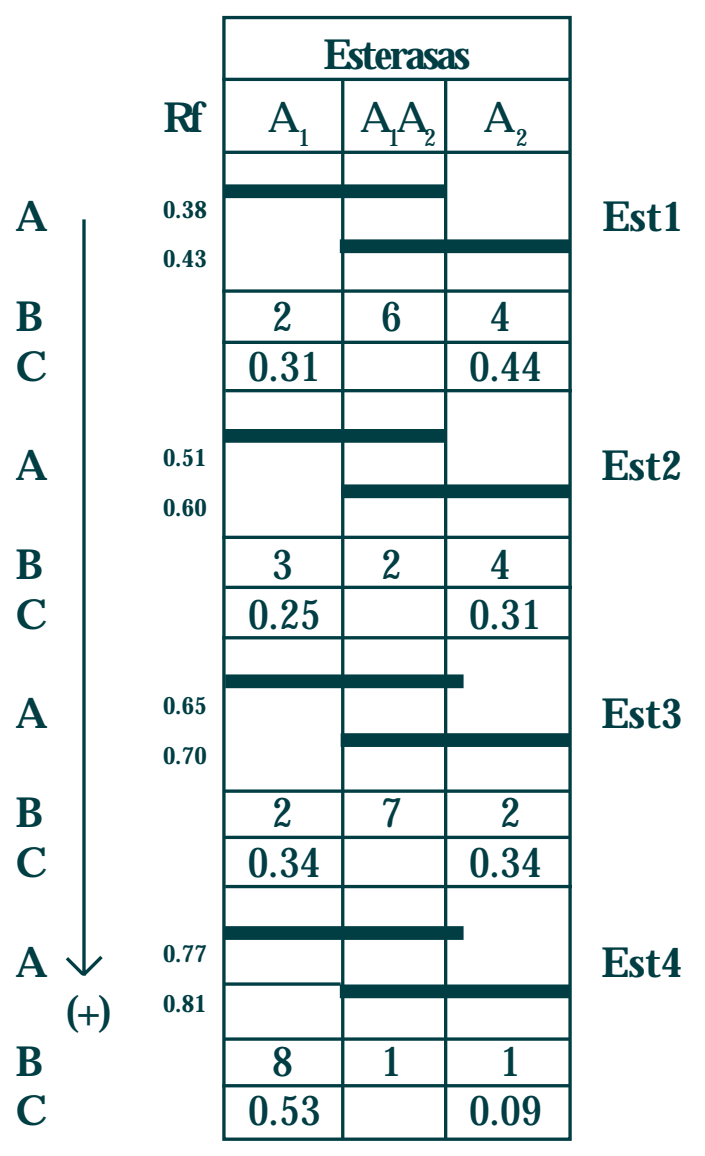

Figura 1. Zimograma del sistema enzimático analizado en Pinus hartwegii Lindl. $A=L$ oci; $B=$ Alelos; $C=$ Frecuencia alélica.

Un análisis integral del nivel de polimorfismo en los sitios con actividad esterasa detectadas revelaron la presencia de un $100 \%$ de polimorfismo isoenzimático en los individuos examinados, lo que denota la presencia de una elevada variación en la composición esterasas en megagametofitos de la población de Pinus hartwegii L indl. examinada.

C abe significar no obstante que estos resultados concuerdan con lo reportado para la mayoría de las especies de Pinus, y en particular coincide con lo encontrado en Pinus taeda por $\mathrm{H}$ amrick et al. (1981). D e igual forma concuerdan con lo obtenido en un trabajo anterior (I glesias y C ruz, 2001, datos no publicados) donde se detectó en la población del C ofre de Perote, Ver . la presencia de un elevado polimorfismo en la composición esterasas de los megagametofitos examinados en dicha población.

L a presencia de un elevado polimorfismo en esta población concuerda además con lo planteado por L edig (1998) en relación a que los pinos constituyen uno delos grupos de organismos mas genéticamente variables del reino vegetal.

Por otra parte el análisis de la base genética de las variantes polimórficas detectadas denotaron la presencia de cuatro loci cada uno con dos alelos $\left(A_{1} A_{1}, A_{1} A_{2}\right.$ y $\left.A_{2} A_{2}\right) L$ a frecuencia genética se encontró dentro del rango de $0.06 \mathrm{a}$ 0.50 . D e igual forma se detectó un valor relativamente el evado de número de al elos por locus (N PA L $=2.8$ ) en esta población. E sto coincide con el número promedio de alelos por locus observados para la mayoría de las especies de Pinusque se han estudiado, que fluctúa en torno al valor de 2.3 (H amrick et al., 1981).

Finalmente y como era de esperar en base al nivel de polimorfismo detectado se observó un elevado valor de heterocigocidad esperada ( $\mathrm{H}$ e $=0.45$ ) valor muy superior al registrado en otras especies del género Pinus (L edig, 1986; B ermejo, 1993). Cabe significar que el parámetro poblacional de heterocigocidad esperada constituye una medida más precisa de la variabilidad genética que el nivel de polimorfismo (A yala y Valentine, 1983).

$L$ a presencia de un exceso de heterocigotos en poblaciones de especies de coníferas no ha sido ampliamente reportado en la literatura (G authier et al., 1992; Beaulieu y Simon, 1995; 
L amy et al., 1999). D eacuerdo con $G$ authier et al. (1992) lo anterior puede deberse a la eliminación de árboles debido a un efecto de depresión consanguínea que pudiese estar actuando tanto a nivel de semillas, plántulas o de árboles jóvenes. $\mathrm{C}$ abe mencionar al respecto que es posible que la presencia de una elevada heterocigocidad observada en esta población sea debida a un efecto marcado de depresión consanguínea que este operando a nivel de semillas. E sto explicaría los bajos valores de viabilidad dela semilla detectados en estudios previos realizados en esta población (Solís e I glesias, datos no publicados). C abe mencionar que se han reportado similares resultados en otras especies de pinos (Linhart et al., 1981; Tigerstedt, 1983). N o obstante, como sugirieran M itton y G rant (1984) los estreses ambiental es pueden también favorecer la presencia de una el evada heterocigocidad en las poblaciones.

E s posible que estudios futuros que se realicen en esta dirección empleando un mayor número de sistemas isoenzimáticos y marcadores moleculares permitan obtener una mayor información para el establecimiento de estrategias apropiadas para el manejo y conservación de esta población.

\section{CONCLUSION ES}

Se detectó un el evado polimorfismo en la composición esterasas en muestras de megagametofito provenientes de la población de Pinushartw egii Lindl. ubicada en el Pico de O rizaba, Ver., las que estuvieron codificadas por 4 loci con 2 alelos.

L os al tos valores detectados en cuanto al número de alelos y heterocigocidad esperada sugieren la existencia de un el evado número de individuos heterocigotos en dicha población que pudiera estar dado por un efecto de depresión consanguínea operando a nivel de semillas lo cual estaría en estrecha concordancia con la baja viabilidad de las semillas observada en la misma.

\section{NOTA DE LA REDACCIÓN:}

Por limitaciones de espacio no se ha podido incluir la lista completa de referencias bibliográficas que acompaña a este artículo. Los interesados en obtenerla en formato electrónico pueden solicitarla directamente a la dirección de correo electrónico de Cuadernos de Biodiversidad. 